\title{
Gene expression profiles of CYP24A1 and CYP27B1 in malignant and normal breast tissues
}

\author{
NAGHMEH ZHALEHJOO ${ }^{1}$, YADOLLAH SHAKIBA ${ }^{2}$ and MOJTABA PANJEHPOUR ${ }^{1}$ \\ ${ }^{1}$ Department of Clinical Biochemistry and Bioinformatics Research Center, School of Pharmacy and Pharmaceutical Sciences, \\ Isfahan University of Medical Sciences, Isfahan 81746-73461; ${ }^{2}$ Department of Immunology, School of Medicine, \\ Tehran University of Medical Sciences, Tehran 14176-13151, Iran
}

Received October 2, 2015; Accepted October 17, 2016

DOI: $10.3892 / \mathrm{mmr} .2016 .5992$

\begin{abstract}
Active vitamin D has several antitumor effects, including prodifferentiative, antiproliferative and proapoptotic functions in a number of tissues via its binding to vitamin D receptor. The 24-hydroxylase (CYP24A1) and 1-hydroxylase (CYP27B1) enzymes are considered to be pivotal determinants of the local concentration of active vitamin $\mathrm{D}$. The aim of the present study was to investigate the mRNA expression levels of the CYP24A1 and CYP27B1 genes in malignant and normal breast tissues. The tumor and adjacent normal tissue samples of 30 patients with breast cancer were acquired from the Iran National Tumor Bank, Imam Hospital (Tehran, Iran). RNA was extracted and, following cDNA synthesis, Taq-Man quantitative polymerase chain reaction analysis was performed for CYP24A1 and CYP27B1. The results demonstrated that the mRNA expression of CYP27B1 was downregulated in the tumor tissues, compared with the adjacent normal tissues $(\mathrm{P}<0.01)$, whereas the mRNA expression of CYP24A1 was significantly upregulated in the tumor tissues $(\mathrm{P}<0.01)$. This major difference revealed that the normal breast tissues transcriptionally expressed CYP24A1 slightly. These results are suggestive of dysregulation of the vitamin D signaling and metabolic pathways during tumorigenesis in breast cancer. Local alterations in the anabolism and catabolism of active vitamin D in breast cancer by the CYP27B1 and CYP24A1 may impair its anticancer functions.
\end{abstract}

\section{Introduction}

There are $\sim 1,000,000$ cases of breast cancer diagnosed annually worldwide (1). Breast cancer is the most frequent and most

Correspondence to: Dr Mojtaba Panjehpour, Department of Clinical Biochemistry and Bioinformatics Research Center, School of Pharmacy and Pharmaceutical Sciences, Isfahan University of Medical Sciences, Hezar Jerib Avenue, Isfahan 81746-73461, Iran E-mail: panjehpour@pharm.mui.ac.ir

Key words: vitamin D, expression, 24-hydroxylase, 1-hydroxylase, breast cancer life-threatening type of cancer among women (2). Various genetic and environmental risk factors may be associated with the incidence of breast cancer, including family history, oral contraceptive pills, menarche and reproductive age, dietary factors, exposure to sunlight, and levels of vitamin D in the blood $(1,3)$.

In addition to its contribution to the regulation of calcium and phosphate metabolism, and its facilitating of bone mineralization (4), the active form of vitamin D (1,25-dihydroxyvitamin D3), termed calcitriol, performs a wide range of biological activities, including proapoptotic, prodifferentiative and antiproliferative effects, in target tissues (3-6) and is able to inhibit the proliferation of human cancer cells (7-9).

The source of the precursor of vitamin D may be through dietary intake or it can be synthesized from 7-dehydrocholesterol in the skin as a result of exposure to ultraviolet $\mathrm{B}$ sunlight $(4,8,10)$. When transferred to the liver, vitamin D3 is hydroxylated in the five carbon side chain and is then converted to 25-hydroxyvitamin D3, which is the major form of vitamin D present in the blood. 25-hydroxyvitamin D3 is also hydroxylated in other tissues, predominantly the kidney, through a mitochondrial enzyme containing cytochrome P450, 1- $\alpha$ hydroxylase (CYP27B1), in the methyl region, which is then converted to 1,25-dihydroxyvitamin D3. This form of vitamin D is bound to vitamin D-binding proteins in the blood stream and activates or represses the transcription of its target gene through binding to the vitamin D receptor (VDR) in tissues $(6,11-13)$. By binding to the retinoid $\mathrm{X}$ receptor, this complex binds to vitamin D response elements in the promoter region of the target genes and regulates the transcription of genes, including those contributing to the regulation of cell growth, differentiation, apoptosis and inflammation, and consequent antitumor activities $(4,5,8)$. Vitamin D decreases the incidence of certain types of cancer via the inhibition of tumor angiogenesis, mutual adherence stimulation of cells and intercellular connection by gap junctions (14). It can also affect hypoxia, the cell cycle and the receptors of hormones, and these effects result in prevention of the progression and metastasis of cancer (15).

The activity of vitamin $\mathrm{D}$ is terminated by the catalytic enzyme, 24-hydroxylase, encoded by CYP24A1 and responsible for vitamin D catabolism, which is then metabolized to 
calcitroic acid, a bile secretion $(1,4,9,10)$. The overexpression of CYP24A1 is associated with a poor prognosis in several types of human cancer, including breast cancer (5). The expression of CYP27B1 can be considered a central mechanism in the association between active vitamin $\mathrm{D}$ and its antitumor effects (12).

These enzymes are active not only in the kidney, but also in several other tissues, including breast tissue $(1,4,9,16)$.

Experimental studies have revealed an association between vitamin $\mathrm{D}$ and protection against breast cancer; vitamin $\mathrm{D}$ levels have been found to be inversely correlated with the risk of breast cancer $(10,17)$. Women with a high dietary intake of vitamin $\mathrm{D}$ have been shown to have a reduced risk of breast cancer $(1,4)$; the risk of breast cancer was found to be five times higher in women with 25-hydroxyvitamin D3 concentrations $<150 \mathrm{nmol} / \mathrm{l}$, compared with women with blood concentrations $>150 \mathrm{nmol} / 1$ (18).

The present study was performed to investigate the expression of CYP27B1 and CYP24A1 in cancerous and normal breast tissues, and to understand their role in the incidence of breast cancer (12). The study was designed to estimate the capacities of cancerous and normal breast tissues to produce local 1,25-dihydroxyvitamin D3, and its importance in controlling the proliferation and differentiation of breast tissue. The results of the present study may be used towards developing preventive or therapeutic measures for breast cancer using precursors of vitamin D.

\section{Materials and methods}

Collection and preparation of tissue samples. Tumor and adjacent normal tissue samples from 30 patients with breast cancer who had undergone surgery were collected and examined from the Tumor Bank, Cancer Institute of Imam Khomeini Hospital (Tehran, Iran). The present study was approved by the ethics committee of Isfahan University of Medical Sciences (Isfahan, Iran). The histopathological results of diagnostic tests of the patients were also collected. Pathological examination confirmed that the normal tissue samples had no malignant signs. The clinical characteristics of the patients are shown in Table I.

RNA extraction and cDNA synthesis. Total RNA was extracted from the homogenized tumor and normal tissues using QIAzol solution (Qiagen GmbH, Hilden, Germany) and an RNeasy Mini kit (Qiagen $\mathrm{GmbH}$ ), respectively, according to the manufacturer's protocols. The RNA concentration was quantified using Nanodrop spectrophotometer, and its quality was determined by electrophoresis on a $1 \%$ agarose gel. Subsequently, the RNA was reverse transcribed into cDNA using a QuantiTect Reverse Transcription kit (Qiagen GmbH) and was prepared for analyzing the gene expression levels of CYP24A1 and CYP27B1.

Quantitative polymerase chain reaction ( $q P C R)$ analysis. qPCR analysis was performed using the TaqMan technique with the ABI Step One Plus system (Thermo Fisher Scientific, Inc., Waltham, MA, USA) and the TaqMan Gene Expression master mix (Thermo Fisher Scientific, Inc.). Assay-on-Demand primers and probes (Thermo Fisher Scientific, Inc.; Table II) were used for detecting the gene expression of CYP24A1 and CYP27B1. The 18S rRNA gene was included as an internal control. Each sample was examined in a final volume of $20 \mu \mathrm{l}$, containing $2 \mu \mathrm{l}$ synthesized cDNA, $10 \mu \mathrm{l}$ master mix and $1 \mu \mathrm{l}$ specific mixed primer and probes. The PCR conditions were as follows: $10 \mathrm{~min}$ at $95^{\circ} \mathrm{C}$, followed by 50 cycles at $50^{\circ} \mathrm{C}$ for $2 \mathrm{~min}$ and $95^{\circ} \mathrm{C}$ for $15 \mathrm{sec}$. The quantification cycle $(\mathrm{Cq})$ values were measured in the samples and the expression levels of the genes were calculated using the $2^{-\Delta \Delta \mathrm{Cq}}$ method (19).

Statistical analysis. Following measurement of the Cq values of the examined genes in the tumor and normal tissue samples and of the internal control gene (18SrRNA), the differences in gene expression between the two groups were examined using the IBM SPSS 19 (IBM SPSS, Armonk, NY, USA) and Microsoft Excel (Microsoft Corporation, Redmond, WA, USA) software programs. In addition, comparison of the gene expression levels of CYP24A1 and CYP27B1 with tumor stage, tumor grade, age range, tumor size and the presence of lymphatic or non-lymphatic invasion were performed using one-way analysis of variance and independent t-tests. $\mathrm{P}<0.05$ was considered to indicate a statistically significant difference. Data are presented as the mean \pm standard deviation.

\section{Results}

Determination of $m R N A$ expression levels of CYP27B1 and $C Y P 24 A 1$. In the present study, the mRNA expression levels of two key enzymes, CYP27B1 and CYP24A1, were examined in breast tumor tissues and adjacent normal tissues using TaqMan RT-qPCR analysis. The data were normalized using the 18SrRNA gene as an internal control. The differences in the expression levels of these two genes in the tumor and normal tissues were examined, and the results were analyzed.

The results showed that the mRNA expression of CYP24A1 was significantly upregulated in the tumorous breast tissue $(\mathrm{P}<0.01)$, compared with the normal tissue, with the mRNA expression of CYP24A1 undetected in certain samples of normal tissue (Fig. 1A).

The analysis of the mRNA expression levels of CYP27B1 in the tumor and normal tissue showed downregulation in the expression of the gene in the tumorous breast tissue $(\mathrm{P}<0.01)$, as shown in Fig 1B.

Determination of the association between demographic parameters and gene expression levels of CYP27B1 and CYP24A1. The comparison of gene expression levels of CYP24A1 and CYP27B1 in the tumor tissues showed no statistically significant difference in the gene expression levels of CYP24A1 between different tumor stages (Fig. 2A), however, there were significant differences between the gene expression of CYP27B1 and tumor stage, in which the gene expression of CYP27B1 at stage 1 was higher, compared with the levels at stage 2 and stage 3 (Fig. 2B).

No statistical differences were found in the gene expression levels of CYP24A1 and CYP27B1 in different tumor grades (Fig. 3A and B).

In examining the association between the gene expression levels of CYP24A1 and CYP27B1 and the age range of 
Table I. Demographic parameters of the subjects.

\begin{tabular}{lc}
\hline Parameter & Subjects; n (\%) \\
\hline Mean age (years) & $50.8 \pm 11.3$ \\
Age range (years) & $32-79$ \\
Tumor stage & \\
T1 & $7(23.3)$ \\
T2 & $20(66.7)$ \\
T3 & $3(10)$ \\
Tumor grade & \\
I & $7(23.3)$ \\
II & $16(53.3)$ \\
III & $7(23.3)$ \\
Tumor size & \\
$<5$ cm & $22(73.3)$ \\
$\geq 5$ cm & $8(26.7)$ \\
Lymphatic invasion & \\
Yes & $17(56.7)$ \\
No & $13(43.3)$ \\
\hline
\end{tabular}

Table II. TaqMan probes for analysis of gene expression.

\begin{tabular}{llc}
\hline Gene & Sequence & $\begin{array}{c}\text { Amplicon } \\
\text { length (bp) }\end{array}$ \\
\hline CYP24A1(FAM-MGB) & Hs00989014 m1 & 108 \\
CYP27B1(FAM-MGB) & Hs01096142 g1 & 74 \\
18S rRNA & Hs99999901 s1 & 187 \\
\hline
\end{tabular}

CYP24A1, 24-hydroxylase; CYP27B1, 1- $\alpha$ hydroxylase.

the patients, the only significant difference was found in the gene expression of CYP24A1 ( $<<0.05$; Fig. 4A), although the gene expression of CYP27B1 increased with increasing age (Fig. 4B).

No statistically significant differences were found between the gene expression levels of CYP24A1 and CYP27B1 and tumor size (Fig. 5A and B).

No statistically significant differences between lymphatic or non-lymphatic invasion and the gene expression levels of CYP24A1 and CYP27B1 were found (Fig. 6A and B).

\section{Discussion}

It has been revealed that vitamin $\mathrm{D}$ has a protective role in inhibiting the growth of proliferating tumor cells, in addition to its role in calcium and phosphate homeostasis $(20,21)$. The two key enzymes, CYP27B1 and CYP24A1 are important in vitamin D anabolism and catabolism, respectively, and are required to maintain adequate levels of vitamin $\mathrm{D}$ in the blood $(13,22)$. In the present study, the mRNA expression levels of CYP27B1 and CYP24A1 were examined in tumorous and normal breast tissues using TaqMan RT-qPCR analysis.
The results showed that the mRNA expression level of CYP27B1 in the normal tissue was higher, compared with that in the tumor tissue, whereas the mRNA expression level of CYP24A1 in the tumor tissue was significantly higher, compared with that in the normal tissue.

As mentioned previously, the active form of vitamin D, calcitriol, performs a wide range of biological activities in target tissues, including proapoptotic, prodifferentiative and antiproliferative effects (3-6). It has been revealed that the progression of cancer is associated with alterations in the balance of the expression of CYP27B1 and CYP24A1, in addition to alterations in the expression of VDR and polymorphisms $(1,23)$.

Anderson et al (5) showed that an increase in the expression of CYP24A1 is found in several types of human tumor, including those of the colon, lung and ovary, although not in tumor tissue of the breast. The results of the present study were not concordant with these in terms of the breast tissue, however, the previous study showed the upregulation of CYP24A1 in colon, lung and ovary tumor tissues $(5,17)$. The results of a study by Fischer et al (17) showed decreased mRNA expression of CYP24A1 in breast carcinoma, compared with benign breast tissue (17), which was also contradictory to the results of the present study.

The study by Anderson et al (5) on cancer cell lines revealed that the induction of CYP24A1 may lead to the metabolism and inactivation of $1,25(\mathrm{OH})_{2} \mathrm{D}_{3}$ and consequently result in the insensitivity of the cells to the growth inhibitory effects of the vitamin. These results conformed to those of a previous study on prostate cancer, showing that the degree of growth inhibition by $1,25(\mathrm{OH})_{2} \mathrm{D}_{3}$ is inversely correlated with the activity of CYP24A1 in cells (5). This can also be estimated using tissue samples, and future investigations aim to examine cell lines.

CYP24A1 is a major target gene of VDR following the binding of vitamin $\mathrm{D}$ to the receptor (10). The product of this gene, which is the major enzyme in the process of vitamin D catabolism, has been identified as an important regulator of the biological effect of the signaling system of vitamin D $(3,24)$. Ren et al (25) showed that the increased expression of CYP24A1 in breast tumors occurs in response to the increased local production of $1,25(\mathrm{OH})_{2} \mathrm{D}_{3}$ in the tissue. Further investigations are required in order to understand the increased expression of VDR or increased levels of vitamin D in the induction of the expression of CYP24A1.

As in the present study, the increased mRNA expression of CYP24A1 has been detected in several types of cancer, including lung, colon, ovary, cervical and esophageal carcinoma, which suggests the involvement of CYP24A1 in tumorigenesis $(10,12)$.

Regarding the significant increase in the mRNA expression of CYP24A1 in malignant cells, several studies have concluded that CYP24A1 can be considered as a potential oncogene in cancer (12,17,26-28). The markedly higher expression levels of CYP24A1 in the tumor tissues examined in the present study support this.

Regarding the mRNA expression of CYP27B1, the present study showed that the expression of CYP27B1 was downregulated in the tumor tissue, compared with that in the normal tissue. The present study found that the tissue synthesis of $1,25(\mathrm{OH})_{2} \mathrm{D}_{3}$ from the blood supplied a local reservoir of vitamin D in the normal breast tissue. 
A

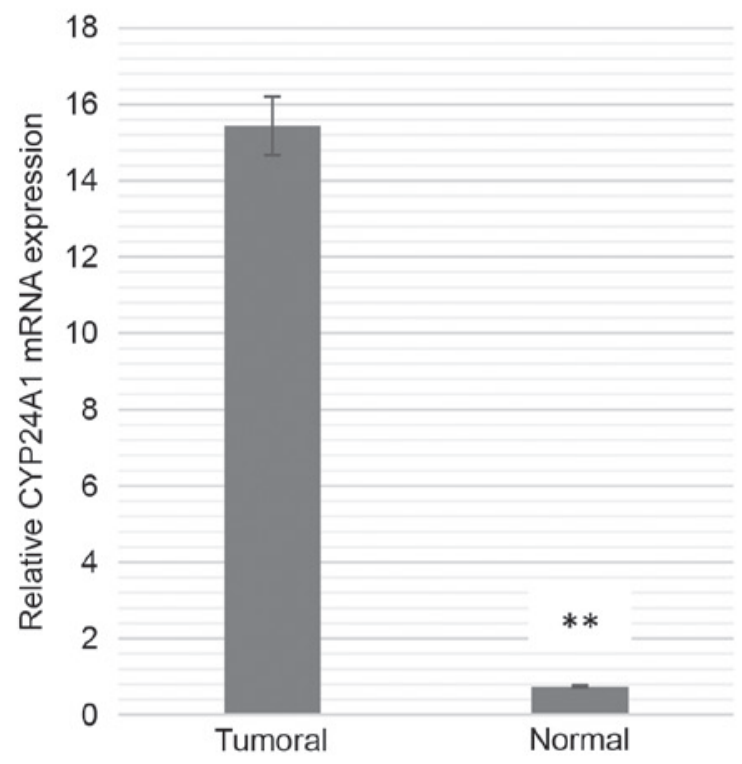

B

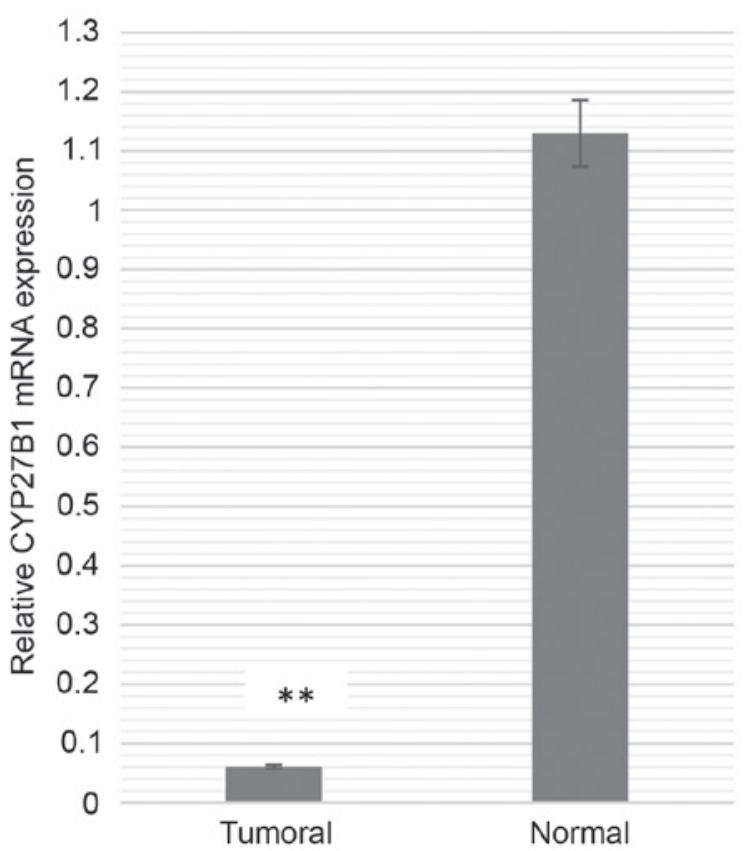

Figure 1. Relative mRNA expression of (A) CYP24A1 and (B) CYP27B1 were determined using reverse transcription-quantitative polymerase chain reaction analysis in breast tissues, with 18SrRNA mRNA as an interna control ( $\left.{ }^{* *} \mathrm{P}<0.01\right)$. CYP24A1, 24-hydroxylase; CYP27B1, 1- $\alpha$ hydroxylase.

In confirmation of the results of the present study, the higher expression of CYP27B1 in the normal breast tissue suggested that the paracrine production of $1,25(\mathrm{OH})_{2} \mathrm{D}_{3}$ may be important for maintaining the safe function of normal breast cells (1). In tumor breast cells, the ability of active vitamin D synthesis is altered and, therefore, VDR-mediated vitamin D function decreases (29).

Previous studies on breast cancer cell lines have revealed that the mRNA expression of CYP27B1 decreases to a certain extent $(7,13)$, which agrees with the present study. However
A



B

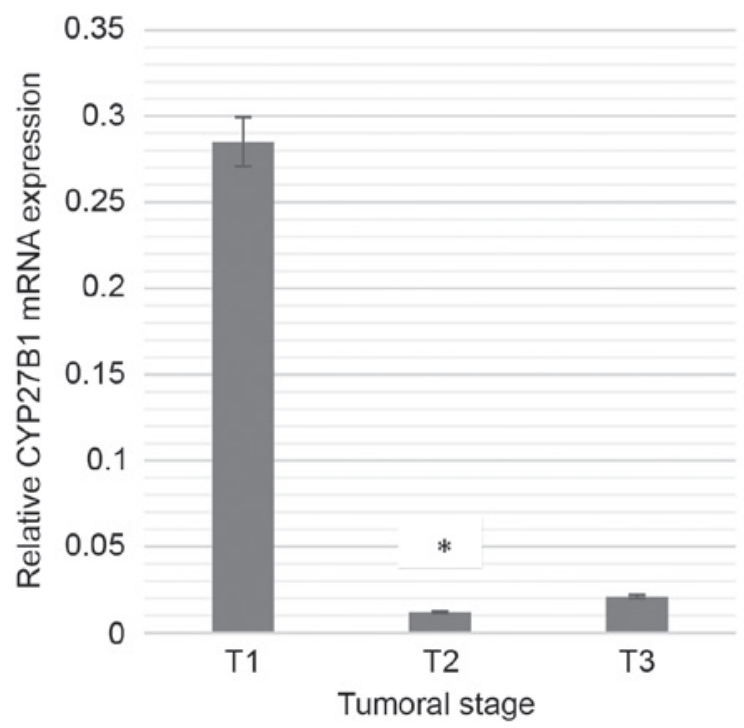

Figure 2. Comparison of the mRNA expression levels of (A) CYP24A1 and (B) CYP27B1 among tumor tissues of different tumor stage. ${ }^{*} \mathrm{P}<0.05$ stage 1 vs. stages 2 and 3. CYP24A1, 24-hydroxylase; CYP27B1, 1- $\alpha$ hydroxylase.

the present study investigated tissue samples. The fact that the activity of CYP27B1 in breast tumor tissue is lower, compared with that in normal breast tissue, and the activity of CYP24A1 is higher, compared with normal breast tissue may indicate potentially malignant deterioration in tumor tissue $(29,30)$.

In the study by Segersten et al (7), the mRNA expression of CYP27B1 in the malignant breast tissue was lower, compared with that in the normal tissue (7). However, Friedrich et al (16) found higher expression levels of CYP27B1 in breast cancer tissue, compared with benign tissue, which may be due to the heterogeneity of the breast cancer (16).

In comparing the mRNA expression of CYP24A1 with tumor stage, tumor grade, age range, tumor size, and lymphatic or non-lymphatic status, the only significant association found 
A

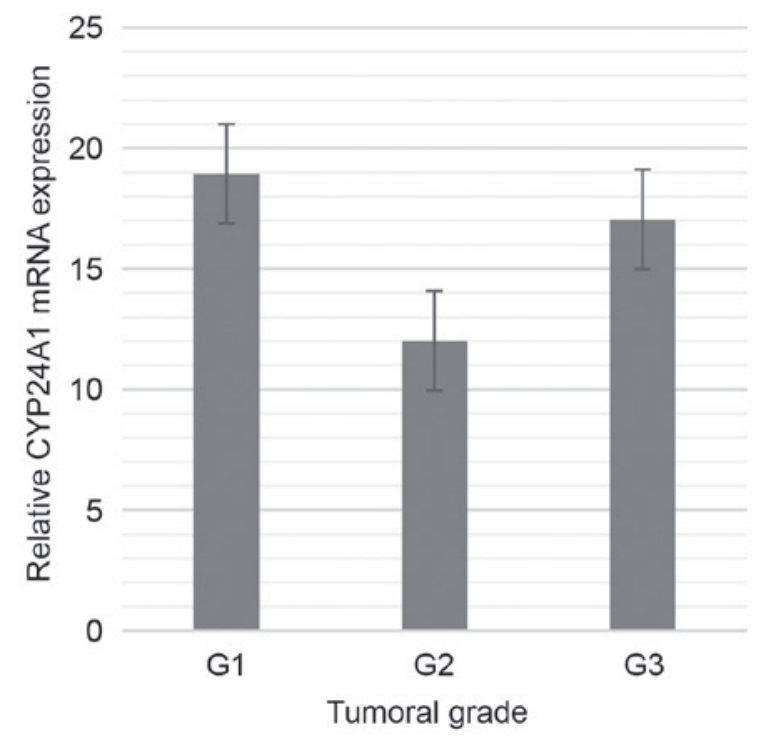

B

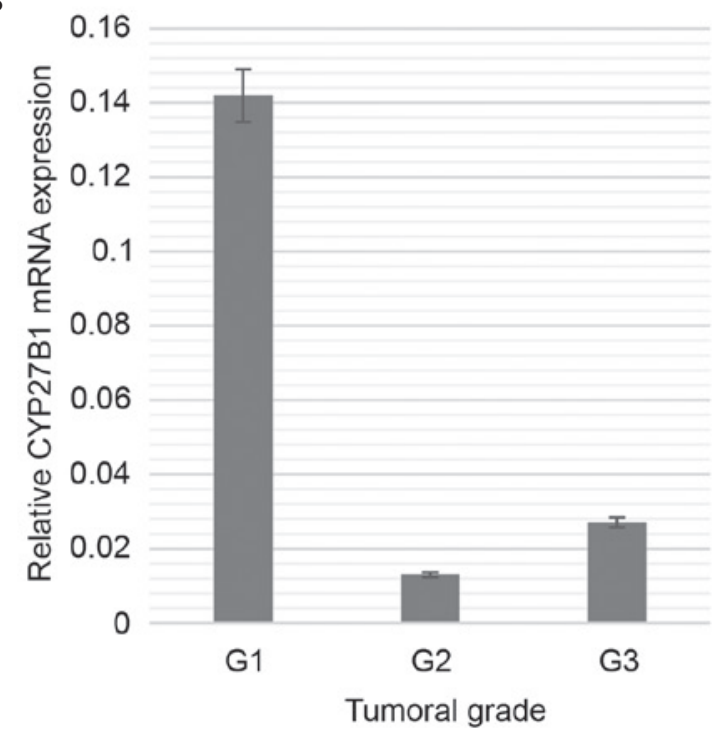

Figure 3. Comparison of the mRNA expression levels of (A) CYP24A1 and (B) CYP27B1 in tumor tissues of different grades. CYP24A1, 24-hydroxylase; CYP27B1, 1- $\alpha$ hydroxylase.

in the present study was between the mRNA expression of CYP24A1 and the age range of the patients. A significant association was also found between the mRNA expression of CYP27B1 and tumor stage. No other significant associations were observed.

In terms of the link between the mRNA expression of CYP24A1 and age range, the results of the present study showed that gene expression levels of CYP24A1 in patients aged $\geq 53$ years were higher, compared with those in patients aged 43-52 years. This finding indicated higher gene expression levels of CYP24A1 at increased patient age and, as a result, the increase in active vitamin $\mathrm{D}$ catabolism during tumorigenesis.

In terms of the association between the gene expression of CYP27B1 and tumor stage, the expression at stage 1 was significantly higher, compared with that at stage 2 . This was
A

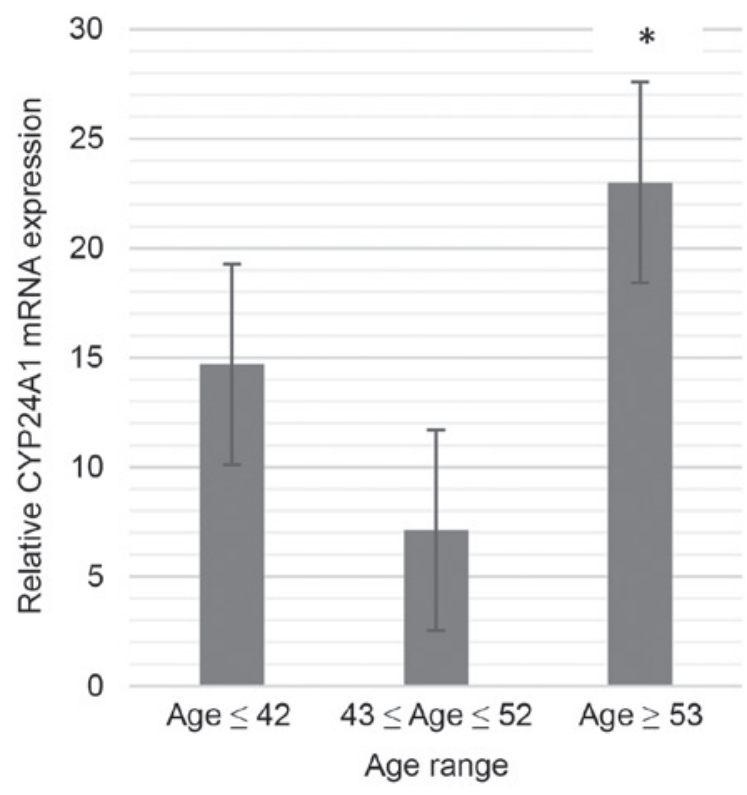

B

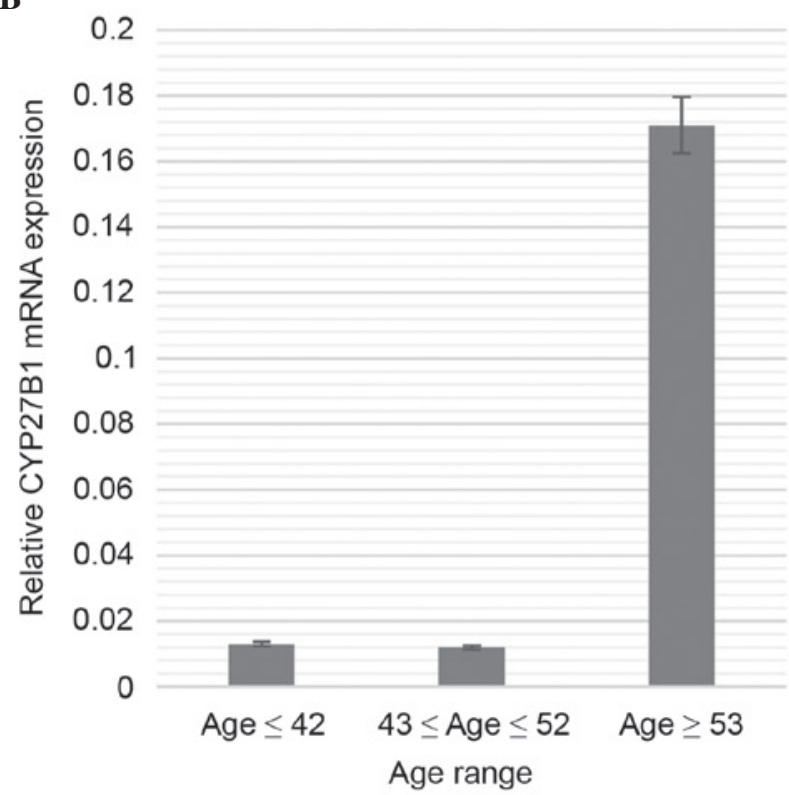

Figure 4. Comparison of the mRNA expression levels of (A) CYP24A1 and (B) CYP27B1 with age range in tumor tissues. ${ }^{*} \mathrm{P}<0.05$ Age $\geq 53$ vs 43 $\leq$ Age $\leq 52$ and Age $\leq 42$. CYP24A1, 24-hydroxylase; CYP27B1, 1- $\alpha$ hydroxylase.

confirmed by the results of the comparison of the gene expression of CYP27B1 in tumor and normal tissues in the present study. The results showed that malignant tissues at a higher stage showed reduced gene expression of CYP27B1, causing a decrease in active vitamin D synthesis.

Epigenetic mechanisms can also silence genes; for example, CYP27B1 is inhibited through alterations in epigenetic methylation (4,31). Investigations performed by McCarthy et al (3) showed that the aberrant methylation of gene promoters is an important mechanism in the progression of breast and colon cancer. Hypermethylation of the CYP27B1 promoter has 
A

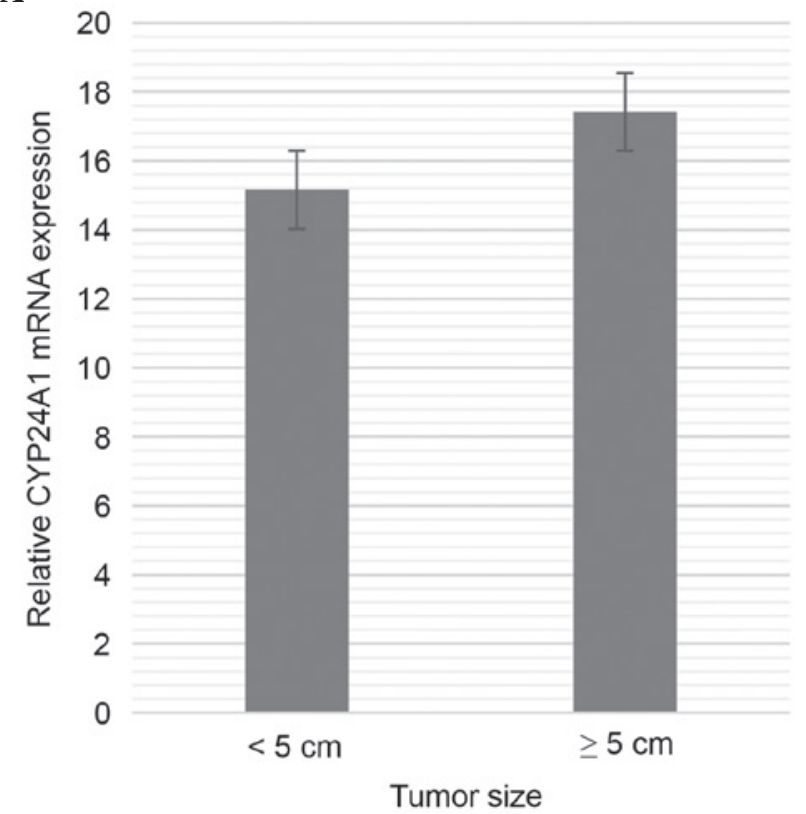

B

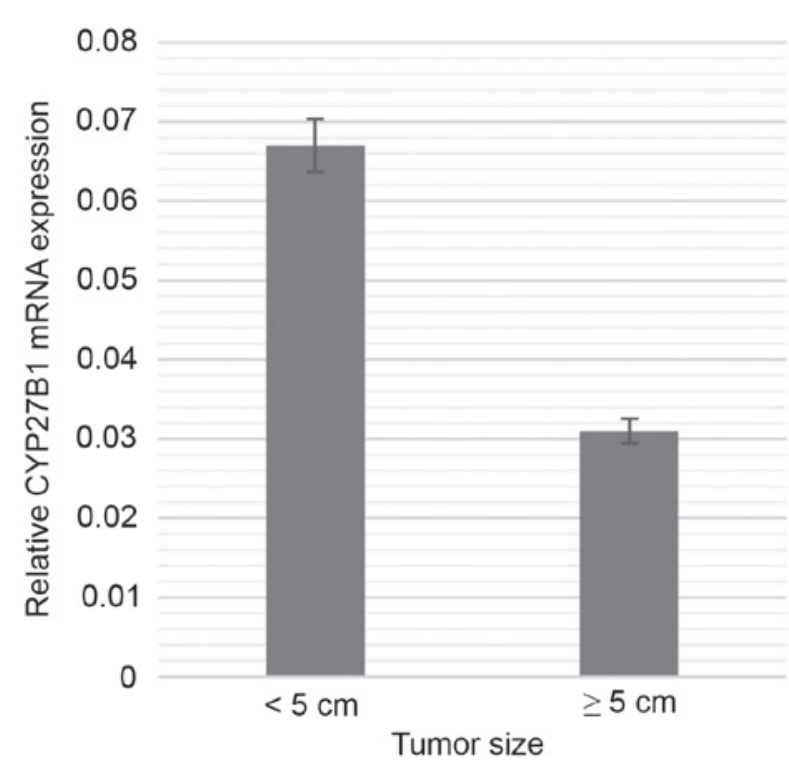

Figure 5. Comparison of the mRNA expression levels of (A) CYP24A1 and (B) CYP27B1 with the size of tumor tissues. CYP24A1, 24-hydroxylase; CYP27B1, 1- $\alpha$ hydroxylase.

been reported in $>40 \%$ of cases of breast cancer, therefore, in breast cancer development, epigenetic alterations can alter gene expression (23), which may be effective in the treatment of cancer using chemopreventive drugs (3).

In addition, women who are exposed to more ultraviolet radiation may be able to neutralize the lower activity of CYP27B1 through supplying more vitamin D (30).

However, polymorphisms in CYP27B1 cause diversity in the regulation of the gene expression (12), a consideration for future investigations.

To compare the mRNA and protein expression levels of protein in CYP27B1 and CYP24A1, further investigations are required in order to examine the expression of CYP27B1 and
A

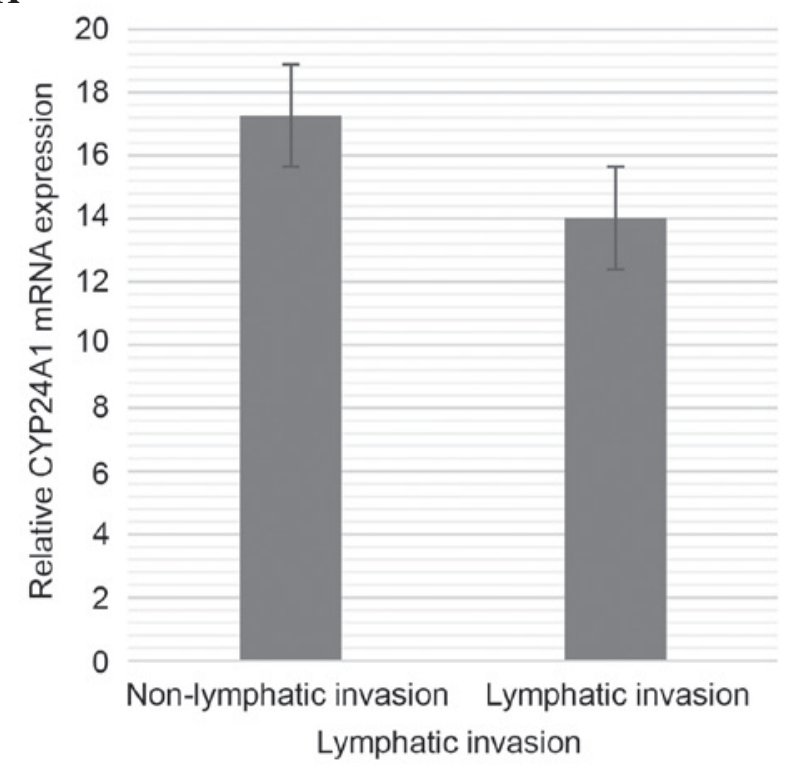

B



Figure 6. Comparison of the mRNA expression levels of (A) CYP24A1 and (B) CYP27B1 with lymphatic invasion in tumor tissues. CYP24A1, 24-hydroxylase; CYP27B1, 1- $\alpha$ hydroxylase.

CYP24A1 using western blot analysis. Studies have shown splice variants in CYP24A1, CYP27B1 and VDR, which may deactivate the enzymes and reduce protein levels $(17,24)$. In addition, assessment of the expression levels of CYP27B1 and CYP24A1 in cancerous and benign breast lesions using immunohistochemistry has shown a reduction in the expression of CYP27B1 and an increase in the expression of CYP24A1 in carcinoma (29). Whether the changes in enzymatic expression can be justified by the serum level of vitamin $\mathrm{D}$, and whether the changes in enzymatic activity are caused by splice variants require consideration in future investigations.

The present study showed that the capacity of local production of active vitamin $\mathrm{D}$ in the breast depends on the presence of 25-hydroxyvitamin D, as the substrate of CYP27B1, and the rate of $1,25(\mathrm{OH})_{2} \mathrm{D}_{3}$ catabolism, which is performed by CYP24A1. 
The results of the present study showed that the breast cells did not completely depend on reserving vitamin $\mathrm{D}$ from systemic sources, and they had the capacity for the local production of $1,25(\mathrm{OH})_{2} \mathrm{D}_{3}$. However, the local production of vitamin $\mathrm{D}$ alters as the tissue becomes cancerous, and the alterations may be involved in the tumorigenesis of the breast cancer (16). Therefore, it can be argued that the disorders in the regulatory system of vitamin D anabolism and catabolism, and the disturbance in the association between VDR, CYP27B1 and CYP24A1 may be involved in the progression of cancer.

Future investigations may enable the detection of vitamin $\mathrm{D}$ analogues with selective anticancer activity, but without systemic side effects or with mild side effects (16). Understanding the alterations in the expression of enzymes effective in the signaling system of vitamin D in tumorigenesis may provide a reasonable basis for using the elements of vitamin D to prevent or treat breast cancer $(12,16,24,28)$.

The results of the present study confirmed the importance of the components of vitamin D anabolism-catabolism in breast cancer, and suggested that evaluating the mRNA expression levels of CYP24A1 and CYP27B1 may be useful for estimating the risk of the progression of breast cancer. Therefore, it can be concluded that breast cells have an enzymatic system producing $1,25(\mathrm{OH})_{2} \mathrm{D}_{3}$, which acts as an autocrine/paracrine growth inhibitor. Increasing the local levels of $1,25(\mathrm{OH})_{2} \mathrm{D}_{3}$ in the tissue through the use of vitamin $\mathrm{D}$ analogues, and performing further investigations on benign and malignant breast cell models of are important in the development of attitudes towards their clinical uses for preventing and treating breast cancer, and for elucidating the role of altered expression in the signaling pathway of vitamin D.

\section{Acknowledgements}

The present study was supported by Isfahan University of Medical Sciences (grant no. 391438).

\section{References}

1. Colston KW, Lowe LC, Mansi JL and Campbell MJ: Vitamin D status and breast cancer risk. Anticancer Res 26: 2573-2580, 2006.

2. Harirchi I, Kolahdoozan S, Karbakhsh M, Chegini N, Mohseni SM, Montazeri A, Momtahen AJ, Kashefi A and Ebrahimi M: Twenty years of breast cancer in Iran: Downstaging without a formal screening program. Ann Oncol 22: 93-97, 2011.

3. McCarthy K, Laban C, Bustin SA, Ogunkolade W, Khalaf S, Carpenter R and Jenkins PJ: Expression of 25-hydroxyvitamin $\mathrm{D}$-1-alpha-hydroxylase and Vitamin $\mathrm{D}$ receptor mRNA in normal and malignant breast tissue. Anticancer Res 29: 155-157, 2009.

4. Haussler MR, Whitfield GK, Kaneko I, Haussler CA, Hsieh D, Hsieh JC and Jurutka PW: Molecular mechanisms of vitamin D action. Calcif Tissue Int 92: 77-98, 2013.

5. Anderson MG, Nakane M, Ruan X, Kroeger PE and Wu-Wong JR: Expression of VDR and CYP24A1 mRNA in human tumors. Cancer Chemother Pharmacol 57: 234-240, 2006.

6. Ordonez-Moran P, Larriba MJ, Pendas-Franco N, Aguilera O, Gonzalez-Sancho JM and Munoz A: Vitamin D and cancer: An update of in vitro and in vivo data. Front Biosci 10: 2723-2749, 2005.

7. Segersten U, Holm PK, Björklund P, Hessman O, Nordgren H, Binderup L, Akerström G and Hellman P: 25-Hydroxyvitamin D3 1alpha-hydroxylase expression in breast cancer and use of non-1alpha-hydroxylated vitamin D analogue. Breast Cancer Res 7: R980-R986, 2005.

8. Wang J and Jiang YF: Natural compounds as anticancer agents: Experimental evidence. World J Exp Med 2: 45-57, 2012.

9. Luo W, Hershberger PA, Trump DL and Johnson CS: 24-Hydroxylase in cancer: Impact on vitamin D-based anticancer therapeutics. J Steroid Biochem Mol Biol 136: 252-257, 2013.
10. Horváth HC, Lakatos P, Kósa JP, Bácsi K, Borka K, Bises G, Nittke T, Hershberger PA, Speer G and Kállay E: The candidate oncogene CYP24A1: A potential biomarker for colorectal tumorigenesis. J Histochem Cytochem 58: 277-285, 2010.

11. Chun RF, Liu PT, Modlin RL, Adams JS and Hewison M: Impact of vitamin D on immune function: Lessons learned from genome-wide analysis. Front Physiol 5: 151, 2014.

12. Townsend K, Banwell CM, Guy M, Colston KW, Mansi JL, Stewart PM, Campbell MJ and Hewison M: Autocrine metabolism of vitamin D in normal and malignant breast tissue. Clin Cancer Res 11: 3579-3586, 2005.

13. Anderson PH, O'Loughlin PD, May BK and Morris HA: Quantification of mRNA for the vitamin D metabolizing enzymes CYP27B1 and CYP24 and vitamin D receptor in kidney using real-time reverse transcriptase-polymerase chain reaction. J Mol Endocrinol 31: 123-132, 2003.

14. Garland CF, Garland FC, Gorham ED, Lipkin M, Newmark H, Mohr SB and Holick MF: The role of vitamin D in cancer prevention. Am J Public Health 96: 252-261, 2006.

15. Aung TT, Chandana SR, D'Silva KJ and Dimitrov NV: The role of vitamin D in breast cancer. Oncol Rev 3: 19-25, 2009.

16. Friedrich M, Diesing D, Cordes T, Fischer D, Becker S, Chen TC, Flanagan JN, Tang pricha V, Gherson I, Holick MF and Reichrath J: Analysis of 25-hydroxyvitamin D3-1alpha-hydroxylase in normal and malignant breast tissue. Anticancer Res 26: 2615-2620, 2006.

17. Fischer D, Becker S, Cordes T, Bücker B, Diedrich K, Friedrich M, Salehin D and Thill M: Vitamin D-24-hydroxylase in benign and malignant breast tissue and cell lines. Anticancer Res 29: 3641-3645, 2009

18. Lowe LC, Guy M, Mansi JL, Peckitt C, Bliss J, Wilson RG and Colston KW: Plasma 25-hydroxy vitamin D concentrations, vitamin D receptor genotype and breast cancer risk in a UK Caucasian population. Eur J Cancer 41: 1164-1169, 2005.

19. Livak KJ and Schmittgen TD: Analysis of relative gene expression data using real-time quantitative PCR and the 2(-Delta Delta C(T)) Method. Methods 25: 402-408, 2001

20. Evans SR, Nolla J, Hanfelt J, Shabahang M, Nauta RJ and Shchepotin IB: Vitamin D receptor expression as a predictive marker of biological behavior in human colorectal cancer. Clin Cancer Res 4: 1591-1595, 1998.

21. Fischer D, Thomé M, Becker S, Cordes T, Diedrich K, Friedrich M and Thill M: 25-Hydroxyvitamin D3 1alpha-hydroxylase splice variants in benign and malignant ovarian cell lines and tissue. Anticancer Res 29: 3627-3633, 2009

22. Fleet JC, DeSmet M, Johnson R and Li Y: Vitamin D and cancer: A review of molecular mechanisms. Biochem J 441: 61-76, 2012.

23. Welsh JE: Vitamin D metabolism in mammary gland and breast cancer. Mol Cell Endocrinol 347: 55-60, 2011.

24. Thill M, Hoellen F, Becker S, Dittimer C, Fischer D, Kümmel S, Salehin D, Friedrich M, Köster F, Diedrich K and Cordes T: Expression of prostaglandin- and vitamin D-metabolising enzymes in benign and malignant breast cells. Anticancer Res 32: 367-372, 2012.

25. Ren S, Nguyen L, Wu S, Encinas C, Adams JS and Hewison M: Alternative splicing of vitamin D-24-hydroxylase: A novel mechanism for the regulation of extrarenal 1,25-dihydroxyvitamin D synthesis. J Biol Chem 280: 20604-20611, 2005.

26. Mimori K, Tanaka Y, Yoshinaga K, Masuda T, Yamashita K, Okamoto M, Inoue $\mathrm{H}$ and Mori M: Clinical significance of the overexpression of the candidate oncogene CYP24 in esophageal cancer. Ann Oncol 15: 236-241, 2004.

27. Tanner MM, Grenman S, Koul A, Johannsson O, Meltzer P,Pejovic T, Borg A and Isola JJ: Frequent amplification of chromosomal region 20q12-q13 in ovarian cancer. Clin Cancer Res 6: 1833-1839, 2000.

28. Albertson DG, Ylstra B, Segraves R, Collins C, Dairkee SH, Kowbel D, Kuo WL, Gray JW and Pinkel D: Quantitative mapping of amplicon structure by array CGH identifies CYP24 as a candidate oncogene. Nat Genet 25: 144-146, 2000.

29. Lopes N, Sousa B, Martins D, Gomes M, Vieira D, Veronese LA, Milanezi F, Paredes J, Costa JL and Schmitt F: Alterations in Vitamin D signalling and metabolic pathways in breast cancer progression: A study of VDR, CYP27B1 and CYP24A1 expression in benign and malignant breast lesions. BMC Cancer 10: 483, 2010.

30. Grant WB: The likely role of vitamin D from solar ultraviolet-B irradiance in increasing cancer survival. Anticancer Res 26: 2605-2614, 2006

31. Bacchetta J, Sea JL, Chun RF, Lisse TS, Wesseling-Perry K, Gales B, Adams JS, Salusky IB and Hewison M: Fibroblast growth factor 23 inhibits extrarenal synthesis of 1,25-dihydroxyvitamin D in human monocytes. J Bone Miner Res 28: 46-55, 2013. 